\title{
Alternatives to exercise challenge for the objective assessment of exercise- induced bronchospasm: eucapnic voluntary hyperpnoea and the osmotic challenge tests
}

\section{Educational aims}

1 To describe alternative tests for the assessment of exercise-induced bronchoconstriction and to describe the mechanisms by which bronchoconstriction is caused.

1 To describe how these tests are performed and how to interpret the test results.

1 To choose the most appropriate test for a given clinical problem.

\section{Summary}

Exercise-induced bronchoconstriction (EIB) is caused by evaporative water loss due to conditioning large volumes of air in a short period. This leads to an increase in osmolarity of the airway surface, which provides a favourable environment for release of bronchoconstricting mediators from inflammatory cells in the airways. Thus, stimuli that mimic this water loss or increase the osmolarity of the airway surface may be used as 'surrogates' for exercise challenge testing. The most widely used tests are eucapnic voluntary hyperpnoea $(\mathrm{EVH})$ or osmotic challenges (e.g. hyperosmolar saline and mannitol). However, there are some differences in the methodology that need to be considered when using these tests. Importantly, EVH and the osmotic challenge tests overcome some of the practical and safety limitations of performing exercise testing at high intensity. The utility of these alternative tests for assessing EIB is discussed.

Exercise testing protocols were developed in the 1970s to identify exerciseinduced bronchoconstriction (EIB), as this was a common feature of persons with currently active asthma $[1,2]$. While exercise testing could be performed both in children and adults, there were practical difficulties with using exercise testing, both in the laboratory and in the field, as well as in the primary care setting, where asthma is most commonly diagnosed and treated, and access to such testing is limited [3].

By the late 1970s, it was realised that water loss by evaporation from the airway surface was the stimulus for EIB and exercise itself was
C. Porsbjerg ${ }^{1}$

J.D. Brannan ${ }^{2}$

${ }^{1}$ Dept of Respiratory and Sleep Medicine, John Hunter Hospital, Newcastle, NSW, and 'Department of Respiratory and Sleep Medicine, Royal Prince Alfred Hospital, Camperdown, NSW, Australia

\section{Correspondence}

C. Porsbjerg

John Hunter Hospital,

Lookout Road

Newlambton

2305 NSW

Australia

porsbjerg@dadlnet.dk

Provenance

Commissioned article, peer reviewed.

\section{Competing interests}

C. Porsbjerg has received honoraria from Pharmaxis for presentations regarding the Aridol test. J.D. Brannan is currently a visiting fellow, which is an unpaid position at the Dept of Respiratory \& Sleep Medicine at Royal Prince Alfred Hospital within the Sydney South West Area Health Service (SSWAHS). The SSWAHS owns the patent for the mannitol test and receives royalties for the sale of Aridol/Osmohale. Since March 2009 he has received $10 \%$ of the royalties for the sale of Aridol/ Osmohale that go to the SSWAH which is approximately US $\$ 9,000$. To date he has received approximately US $\$ 9,000$ in consulting fees for Pharmaxis which includes a fee for speaking on two occasions. He own shares in Pharmaxis that he purchased himself that are currently valued at US $\$ 20,000$. He has acted as a consultant to MedImmune Ltd (US\$4,000) and Wyeth Ltd (US\$1,500). 


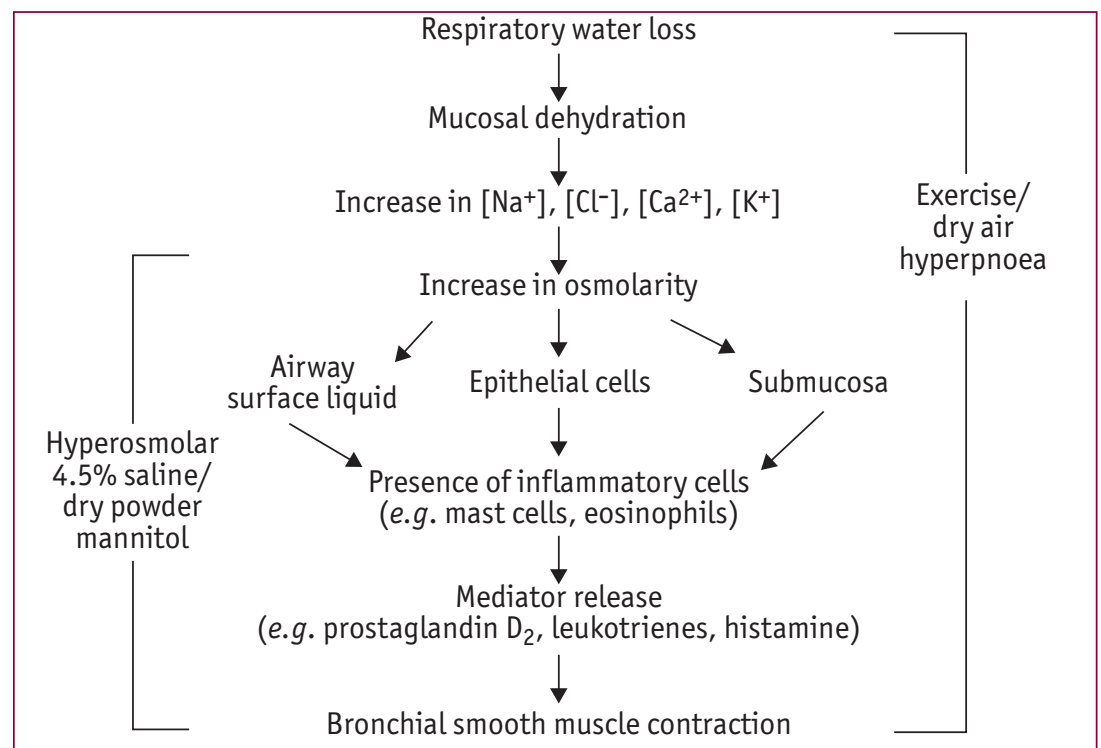

\section{Figure 1}

A schematic outlining the key events that result in bronchial hyperresponsiveness due to hyperpnoea with dry air in persons with asthma that occurs during or following vigorous exercise or a eucapnic voluntary hyperventilation challenge. The osmotic challenge tests using hypertonic saline or mannitol mimic the effects of dry air hyperpnoea by increasing the osmolarity of the airway surface. For all these stimuli, the presence of airway inflammation in association with a sensitive airway smooth muscle is important. Reproduced from [4], with permission from the publisher. not necessary to provoke the response. This recognition led to the development of the eucapnic voluntary hyperpnoea $(\mathrm{EVH})$ test which utilises dry air to mimic the airway dehydration of hyperpnoea during exercise. Dehydration of the airway surface liquid leads to an increase in osmolarity, which causes inflammatory cells in the airways to release bronchoconstricting mediators. This understanding formed the basis of the subsequent development of hyperosmolar saline and dry powder mannitol as alternatives to $\mathrm{EVH}$ in the diagnosis of ElB (fig. 1).

These alternative tests also proved useful for identifying subjects who were at risk of EIB. Specifically, among groups such as elite athletes, defence force recruits and divers with self-contained underwater breathing apparatus (SCUBA), for whom EIB may be hazardous, an objective measure is important. The development of $\mathrm{EVH}$ and the osmotic challenges provided practical advantages over exercise testing.
Forced expiratory volume in $1 \mathrm{~s}\left(\mathrm{FEV}_{1}\right)$ is the preferred measure of airway calibre for each test and at least two reproducible FEV 1 values are recorded, and the best FEV1 value is used to calculate the airway response. Furthermore, medications for the treatment of asthma need to be avoided at different times prior to testing, such that these drugs do not influence the airway response to these tests (table 1). Testing for EIB requires a subject to perform exercise vigorously for 6-8 min, a requirement that limits usefulness in some children and adults, particularly the elderly or impaired (e.g. obese). Furthermore, the "bolus dose" of the exercise stimulus for EIB testing is such that large decreases in FEV1 may occur postexercise. Testing for EIB requires several trained personnel to be in attendance for up to an hour, adding significantly to the expense of the test. Finally, the equipment required to perform the exercise adequately (e.g. treadmill or bicycle ergometer) can be expensive and occupies a large amount of space. Both EVH and the osmotic challenges have improved access to bronchial provocation testing while maintaining or improving the diagnostic utility of testing.

EIB is common in persons with clinical signs and symptoms of asthma, but it also occurs in persons who do not have clinical signs and symptoms. In both subject groups, the clinical decision for treatments to prevent EIB is similar, i.e. by using medications effective for the treatment of clinical asthma. It has been appreciated more recently that the clinical signs and symptoms of asthma are not reflective of the degree of pathophysiology that is sensitive to inhaled corticosteroids. However, airway responses to exercise and these alternative tests have been demonstrated to relate to the degree of steroid-sensitive inflammation $[5,6]$. Thus, such tests hold some

\section{Table 1 Required periods for withholding medications, food and activity before challenge tests}

$\begin{array}{ll}\text { Medication } & \text { Time } \\ \text { Inhaled, nonsteroidal anti-inflammatory agents e.g. sodium cromoglycate and nedocromil sodium } & 6-8 \mathrm{~h} \\ \text { Short-acting } \beta_{2} \text {-agonists e.g. salbutamol and terbutaline } & 8 \mathrm{~h} \\ \text { Inhaled corticosteroids e.g. beclomethasone dipropionate, budesonide, fluticasone propionate, } & 12 \mathrm{~h} \\ \text { ciclesonide and mometasone furoate } & 12 \mathrm{~h} \\ \text { Ipratropium bromide } & 24 \mathrm{~h} \\ \text { Inhaled corticosteroids plus long-acting } \beta_{2} \text {-agonists e.g. fluticasone and salmeterol, } & 24 \mathrm{~h} \\ \text { budesonide and eformoterol } & 24 \mathrm{~h} \\ \text { Long-acting } \beta_{2} \text {-agonists e.g. salmeterol and eformoterol } & 72 \mathrm{~h} \\ \text { Theophylline } & 72 \mathrm{~h} \\ \text { Tiotropium bromide } & 4 \text { days } \\ \text { Antihistamines e.g. cetirizine, fexofenadine and loratadine } & \\ \text { Leukotriene-receptor antagonists e.g. montelukast sodium } & 6 \mathrm{~h} \\ \text { Food and activity } & 12 \mathrm{~h} \\ \text { Caffeinated drinks e.g. coffee and cola drinks } & \end{array}$


promise to more effectively identify the need for treatment and to monitor efficacy of treatment in those with EIB [7].

This review covers only indirect stimuli as an alternative to exercise. It is not intended to be a comparison between direct and indirect tests for identifying bronchial hyperresponsiveness (BHR) and for this the reader is referred elsewhere [8].

\section{EVH}

EVH (also known as eucapnic hyperventilation or isocapnic hyperventilation) was developed from the understanding that the ventilation reached and sustained, and the water content of the air inspired were important determinants of bronchoconstriction in asthmatics with documented EIB $[9,10]$. EVH is now well established as a surrogate for exercise in the diagnosis of EIB [11-14]. The characteristics of the airway response to these stimuli are very similar, although there are differences in the physiological and metabolic demands between $\mathrm{EVH}$ and exercise: for example, the maximum airway response, measured as a decrease in FEV1, usually occurs within 10 min of cessation of hyperpnoea, with the median time to achieve the maximum response being only 4 min for $\mathrm{EVH}$. The airway sensitivity to a progressive challenge with EVH can be predictive of the decrease in FEV1 in response to exercise (fig. 2) and the drugs that inhibit EIB also inhibit the response to $\mathrm{EVH}$. Refractoriness to the stimulus, usually defined as $<50 \%$ of the initial FEV1 response, is observed with repeated exercise and EVH within 1-4 h.

\section{Rationale and development}

A standardised protocol, originally developed to screen defence force recruits for EIB, uses a special gas mixture inhaled at room temperature for 6 min with a target ventilation of 30 times the FEV 1 [12]. While cooling the air can reduce the time of the challenge and the ventilation required, it is expensive and, for most assessments, unnecessary. However, in young children, a protocol of 4 min hyperpnoea in cold air has been developed and used very successfully [16] and there is even a protocol for 2-yrolds [17]. The equipment required to perform an $\mathrm{EVH}$ challenge requires less space than exercise equipment and only one person is required for testing (fig. 3) [14]. It is important that eucapnia (38-42 mm Hg) is maintained during an $\mathrm{EVH}$ challenge, as hypocapnia is a well-known bronchoconstricting stimulus. Eucapnia is maintained by providing a source of

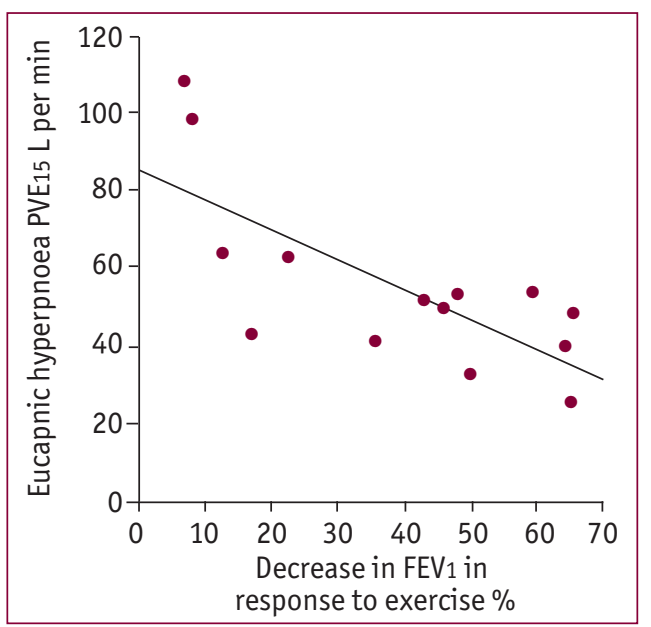

Figure 2

The relationship between PVE15 (the provocative ventilation required to induce a $15 \%$ decrease in FEV1) obtained during a multistage eucapnic voluntary hypopnoea challenge test in known asthmatic subjects and its relationship to the decrease in FEV1 following 8 min of exercise on a cycle ergometer breathing dry air. $r=$ $-0.73 ; p<0.001$. Reproduced from [15], with permission from the publisher.

dry air containing 4.9-5.0\% carbon dioxide $\left(\mathrm{CO}_{2}\right)$ and $21 \%$ oxygen, balanced with nitrogen. This mixture keeps end-tidal $\mathrm{CO}_{2}$ levels within the normal or eucapnic range when minute ventilation is 40-105 L per min, provided a subject has an FEV1 of $1.5 \mathrm{~L}$ or more [18]. If a subject has a level of ventilation value beyond this range (e.g. elite athletes) then a mixing device can be used to adjust and monitor the $\mathrm{CO}_{2}$ concentration to maintain eucapnia. The level of ventilation that is required depends on the subject tested: for elite athletes and others performing high-intensity exercise it is calculated as 30 times the $F E V 1$, which represents $75-85 \%$ of the achievable maximum voluntary

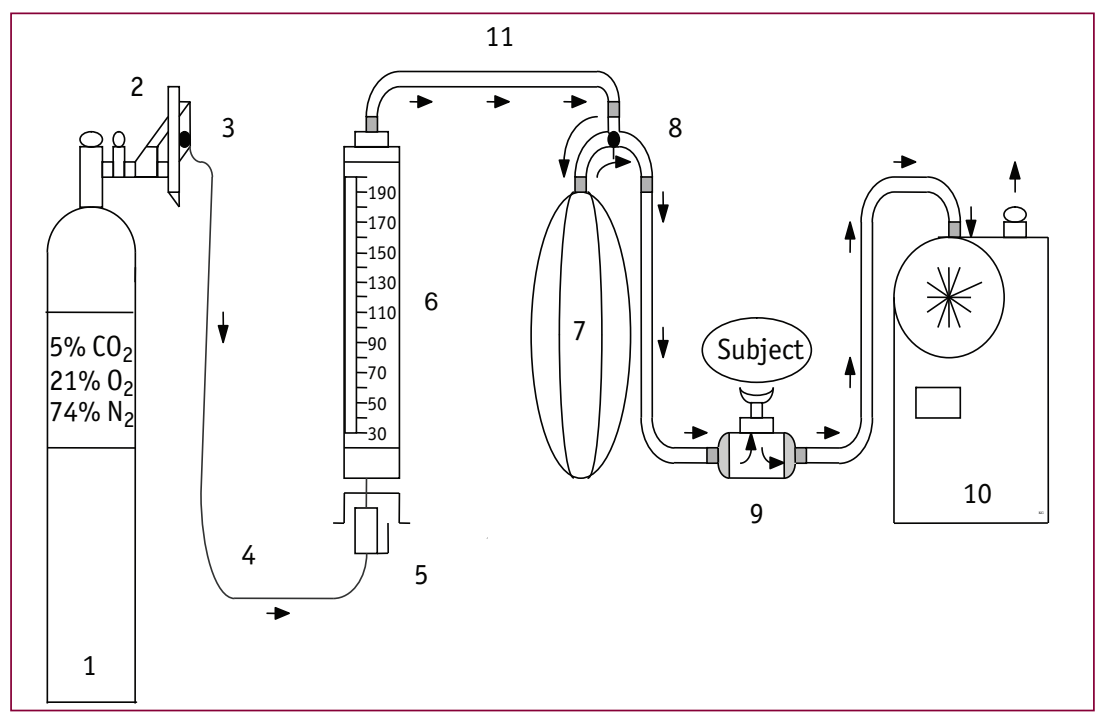

\section{Figure 3}

An example of the basic equipment used to perform a eucapnic voluntary hyperpnoea test. 1: compressed gas mixture; 2: regulator; 3: demand resuscitator, 30-150 L per min; 4: high-pressure tubing; 5: demand valve; 6: rotameter, 30- 200 L per min; 7: meteorological balloon, 100$300 \mathrm{~g}$; 8: metal connector with tap that simultaneously allows gas both to enter and leave balloon; 9: low-resistance, low dead-space breathing valve; 10: gas meter accurate to $1 \mathrm{~L} ; 11$ : hoses, minimum diameter 1.25 inches. Arrows indicate direction of gas flow. Note: equipment substitutions can be made for 1 and 10 by using a commercial gas mixer and a high flow-rate meter turbine to measure ventilation, which will add cost to the basic equipment. Reproduced from [15], with permission from the publisher. 


\section{Educational questions}

1. What are the main limitations to the exercise challenge test?

2. Which are the main alternatives to exercise testing?

3. Through which mechanisms do the alternative tests induce bronchoconstriction?

4. What is the advantage of eucapnic voluntary hyperpnoea $(\mathrm{EVH})$ over the osmotic challenge tests?

5. What are the advantages of the osmotic challenge tests over $\mathrm{EVH}$ ? ventilation (MW). For most subjects not competing at elite level, a ventilation exceeding 21 times the $\mathrm{FEV}_{1}(60 \% \mathrm{MW})$ is likely to be close to the maximum ventilation achieved during exercise in a test for EIB [19]. In a pulmonary function laboratory setting, $81 \%$ of the patients referred for testing for EIB were able to achieve this target [20]. The minimum level for a valid test may be set as low as 17.5 times the FEV 1 for 6 min to be consistent with exercise ventilation [19]. The actual target ventilation is based on the subject's reproducible pre-challenge $\mathrm{FEV} 1$ and is independent of the subject's physical fitness.

It should be noted that the reduction in FEVI following $\mathrm{EVH}$ is not related to the pre-challenge $\mathrm{FEV} 1$ and even in those with normal predicted values for $\mathrm{FEV}_{1}$, the decreases can commonly exceed $30 \%$, and sometimes $50 \%[21,22]$. This may be important to consider when testing subjects who are taking $\beta_{2}$-agonists on a daily basis, as it has been observed that these subjects can have a more pronounced decrease in FEV 1 , as well as a slower airway recovery following EIB with a standard dose of rescue $\beta_{2}$-agonist [23].

\section{Protocol}

The single 6-min protocol is the most commonly used $[12,14]$; however, in persons with suspected asthma, a multistage protocol has been developed which requires 3 -min periods of ventilation at 10.5, 21 and 31 times FEV 1 [24]. A 4-min protocol at 21 times $\mathrm{FEV} 1$ has also been used in known asthmatics to evaluate the protective effect of drugs [25].

Some systems use demand valves directly attached to the source of gas and incentive devices on computer screens to help the subject achieve the target ventilation. One fairly inexpensive system (fig. 3) [26] uses a large, powderfree meteorological balloon as a reservoir. The balloon is filled with $\geq 90 \mathrm{~L}$ of the dry air containing $\mathrm{CO}_{2}$. The subject inhales the air through a two-way valve and is asked to hyperventilate voluntarily to keep the balloon at a constant volume while the gas from the cylinder refills the balloon via a rotameter at the target rate. An advantage of systems that measure ventilation during the EVH test is the ability to observe sudden decreases in ventilation that may be due to bronchospasm. In such cases, the test should be stopped and FEV1 should be measured immediately. At the end of the period of ventilation, $\mathrm{FEV} 1$ is measured in duplicate immediately post-challenge and for 3, 5, 10, 15 and 20 min. If using a multistage protocol in known asthmatics, measurements of
FEV 1 are made more at 1, 3, 5 and $7 \mathrm{~min}$, and if there is no further decrease at $7 \mathrm{~min}$, the subject proceeds to the next level of ventilation [26]. However, progressive protocols can induce refractoriness at the higher ventilations [27].

\section{Interpreting the response to EVH tests}

A decrease in $\mathrm{FEV} 1$ from the pre-challenge value of $\geq 10 \%$ is defined as a positive test result based on the mean plus two standard deviations of healthy, nonasthmatic subjects. When minute ventilation is $\geq 60 \%$ of $\mathrm{MW}_{\text {, decreases in }} \mathrm{FEV}_{1}$ of $10-19.9 \%$ and $20-29.9 \%$ are classified as mild and moderate, respectively. A decrease in FEV1 $>30 \%$ is considered severe at any ventilation (fig. 4) $[14,26]$. The decrease in FEV1 should be sustained, with the subject having a 10\% decrease in $\mathrm{FEV}_{1}$ recorded at two consecutive time points post challenge [28]. EVH has been observed to identify more cases of EIB than laboratory exercise tests and is as sensitive as field exercise testing [29]. This is probably due to the higher levels of ventilation that can be achieved rapidly and sustained using EVH compared with exercise on a bicycle or treadmill in a laboratory. Thus, persons with mild EIB and a negative response to a laboratory exercise protocol may have a positive response to the 6-min dry air voluntary hyperpnoea EVH protocol.

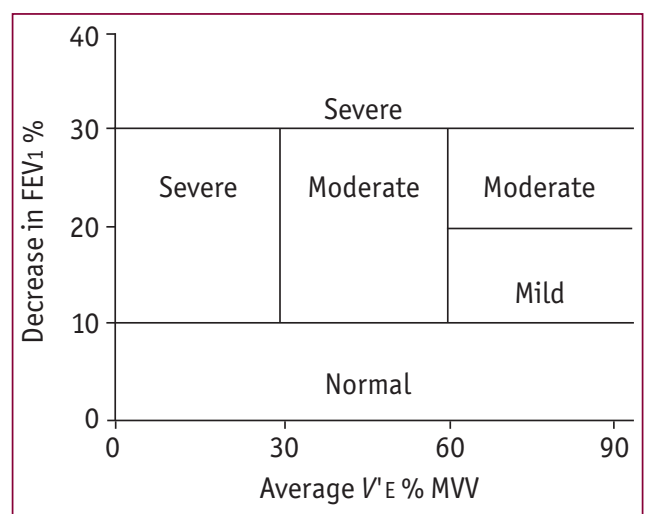

\section{Figure 4}

The classification of severe, moderate and mild EIB for an EVH challenge for either a single- or multistage protocol. Severity is based on the level of ventilation required to induce a positive response. For example, if a subject has a $10 \%$ decrease in FEV1, the response is classified as severe if the ventilation required was $<30 \%$ of $M W$, moderate if it is $<60 \%$ MW or mild if $>60 \%$ MW. A decrease in FEV 1 of $>30 \%$ is considered severe, independent of the level of ventilation. V'E: minute ventilation 


\section{Hyperosmolar saline challenge test}

Hyperosmolar saline was established as a laboratory-based test for identifying the presence of asthma without the need for tests using a source of dry air $[30,31]$. The immediate practical advantages are that this test requires a small amount of equipment and the progressive dose-response nature of the protocol means that severe decreases in FEV1 can be avoided. The hyperosmolar saline challenge has been used safely in epidemiological studies of BHR [32, 33]. The safety of hyperosmolar saline has been established in phase 3 clinical trials [34]. While assessing BHR with hyperosmolar saline, the associated induction of sputum can also be performed for the identification of sputum cell types [35].

\section{Rationale and development}

The protocol for the delivery of hyperosmolar saline as a bronchial provocation test was established in the 1980s [30]. It was found that the rate of change of airway osmolarity was the most important determinant of the response. A standardised protocol was developed using a concentration of $4.5 \%$ saline [31]. Higher concentrations caused the $\mathrm{FEV}_{1}$ to decrease too quickly and, for lower concentrations, the time for testing was too long. The aerosol is administered in progressively increasing doses with the subject inhaling for increasing time intervals until the desired minimum decrease in FEV1 is achieved. This progressive dose-response protocol has advantages of safety over both EVH and exercise, where the stimulus is given as a bolus dose over 6-8 min. Initially, a value of $20 \%$ decrease in $\mathrm{FEV} 1$ from the pre-challenge value was used for $4.5 \%$ saline [31]. This value was reduced to a $15 \%$ decrease in $\mathrm{FEV} 1$, as it became evident that healthy subjects with normal lung function had little response [36]. This value of $15 \%$ was confirmed in a later study in healthy subjects based on the mean plus two standard deviations of the $\%$ decrease in FEV1 [34].

\section{Protocol}

The equipment required is a large-volume (200$250 \mathrm{~mL}$ ) ultrasonic nebuliser with a detachable canister (for weighing) that generates particles 2-6 $\mu \mathrm{m}$ in diameter and delivers $1.5-2 \mathrm{~mL}$ per $\min$ to the inspiratory port of the two-way valve. The canister is filled with $200 \mathrm{~mL}$ of $4.5 \%$ saline at $\sim 21^{\circ} \mathrm{C}$ and the subject breathes tidally through a two-way valve for different periods of exposure. The aerosol is inspired through tubing with a smooth interior about $60-70 \mathrm{~cm}$ long and 22 $\mathrm{mm}$ wide to avoid excessive impaction of the aerosol. All of the specifications reduce variability of the output of the nebuliser [26].

The prechallenge FEV1 is measured in triplicate. The initial exposure is $30 \mathrm{~s}$ followed $60 \mathrm{~s}$ later with two reproducible FEV1 measurements. If the reduction in FEV1 is $<15 \%$ of the pre-challenge $\mathrm{FEV} 1$, then the next exposure time is doubled (e.g. the remaining doses are $60 \mathrm{~s}, 2 \mathrm{~min}$, 4 min and $8 \mathrm{~min}$ ). If the FEV1 decreases $\geq 10 \%$ but $<15 \%$ between each dose, the previous dose is repeated. The test is completed when a 15\% decrease in FEV1 is achieved or a minimum dose of $\geq 23 \mathrm{~g}(\sim 23 \mathrm{~mL})$ of aerosol has been delivered following the final dose of $8 \mathrm{~min}$ (total exposure time $15.5 \mathrm{~min}$ ). The dose is measured by reweighing the detachable canister and tubing (without the two-way valve) making sure that any aerosol that has deposited in the tubing is permitted to fall back into the canister and not be excluded from the reweighing procedure. The dose delivered in $\mathrm{mL}$ per exposure time is calculated [26].

\section{Interpreting the response to hyperosmolar saline}

A dose-response curve is constructed relating the percentage fall in $\mathrm{FEV}_{1}$ to the cumulative dose of aerosol delivered in $\mathrm{mL}$. The provocative dose causing a $15 \%$ decrease in $\mathrm{FEV}_{1}$ (PD15) is calculated via linear interpolation. A PD15 value $<2 \mathrm{~mL}$ is classified as severe, 2-6 mL as moderate and $>6 \mathrm{~mL}$ as mild (fig. 5) [26]. Epidemiological studies have demonstrated that a positive response to hyperosmolar saline is associated with currently active asthma [33, 37]. Subjects hyperresponsive to $4.5 \%$ saline have been shown to be less responsive following treatment with inhaled corticosteroids (ICS) [36, 38, 39]. For subjects already taking ICS who are also hyperresponsive to $4.5 \%$ saline, it is likely they could benefit from a higher dose of ICS or improved adherence to ICS. A negative response to hyperosmolar saline in the presence of ICS may suggest very mild or controled asthma [40]. There have been a number of studies demonstrating a relationship with the airway sensitivity to hyperosmolar saline and the airway response to exercise [41-43]. In one study of 365 school children who exercised and had a hyperosmolar (4.5\%) saline test, the sensitivity and specificity of hyperosmolar saline to identify EIB was $54 \%$ with a specificity of $85 \%$ [32]. To 


\section{Figure 5}

The classification of the airway response to hypertonic saline. This is calculated using the dose of aerosol required to provoke a $15 \%$ decrease in FEV1 from the pre-challenge value. The delivered dose (in $\mathrm{mL}$ ) is cumulative and is calculated by dividing the total dose delivered over the total time required to administer the challenge. An abnormal response is two standard deviations over the mean healthy response (normal <15\%). Circles: severe $(<2 \mathrm{~mL})$; squares: moderate (2.1-6 mL); diamonds: mild (>6 $m L)$. Reproduced from [15] with permission from the publisher.

\section{Figure 6}

Examples of equipment used to perform a) laboratory exercise testing, b) exercise testing in the field, c) eucapnic voluntary hyperpnoea, and d) hypertonic saline and e) mannitol challenge tests.

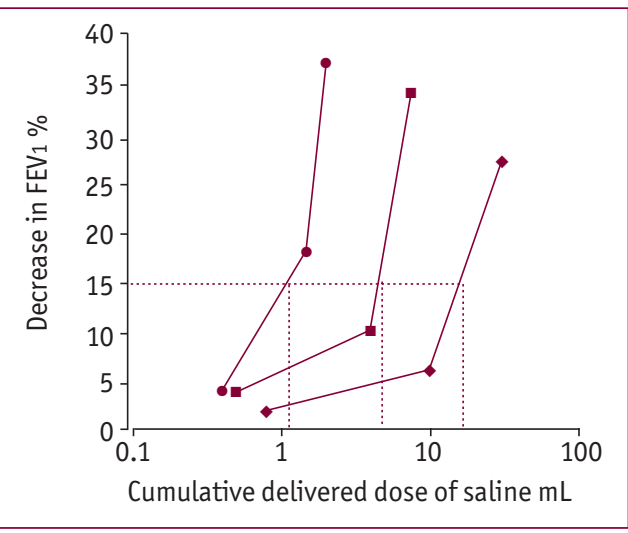

date, there have been no studies assessing the efficacy of hypertonic saline to diagnose EIB in athletes. The sensitivity and specificity of hyperosmolar saline has been assessed in a population of adults where it was found to have a specificity of $65 \%$ to identify a clinical diagnosis of asthma, with a specificity of $95 \%$ [34]. In this study, the mean decrease in $\mathrm{FEV} 1$ was $21.0 \pm 5.7 \%$; a $15 \%$ decrease was the target for diagnosis.

\section{Mannitol airway challenge test}

The mannitol challenge test uses capsules of drypowder mannitol delivered via a simple inhaler. Anderson et al. [44] first developed the mannitol bronchial challenge test in 1996. A mannitol test kit (Aridol ${ }^{\mathrm{TM}} /$ Osmohal $^{\mathrm{TM}}$ ) is now commercially available in Australia and 18 countries in Europe and Asia (fig. 6)
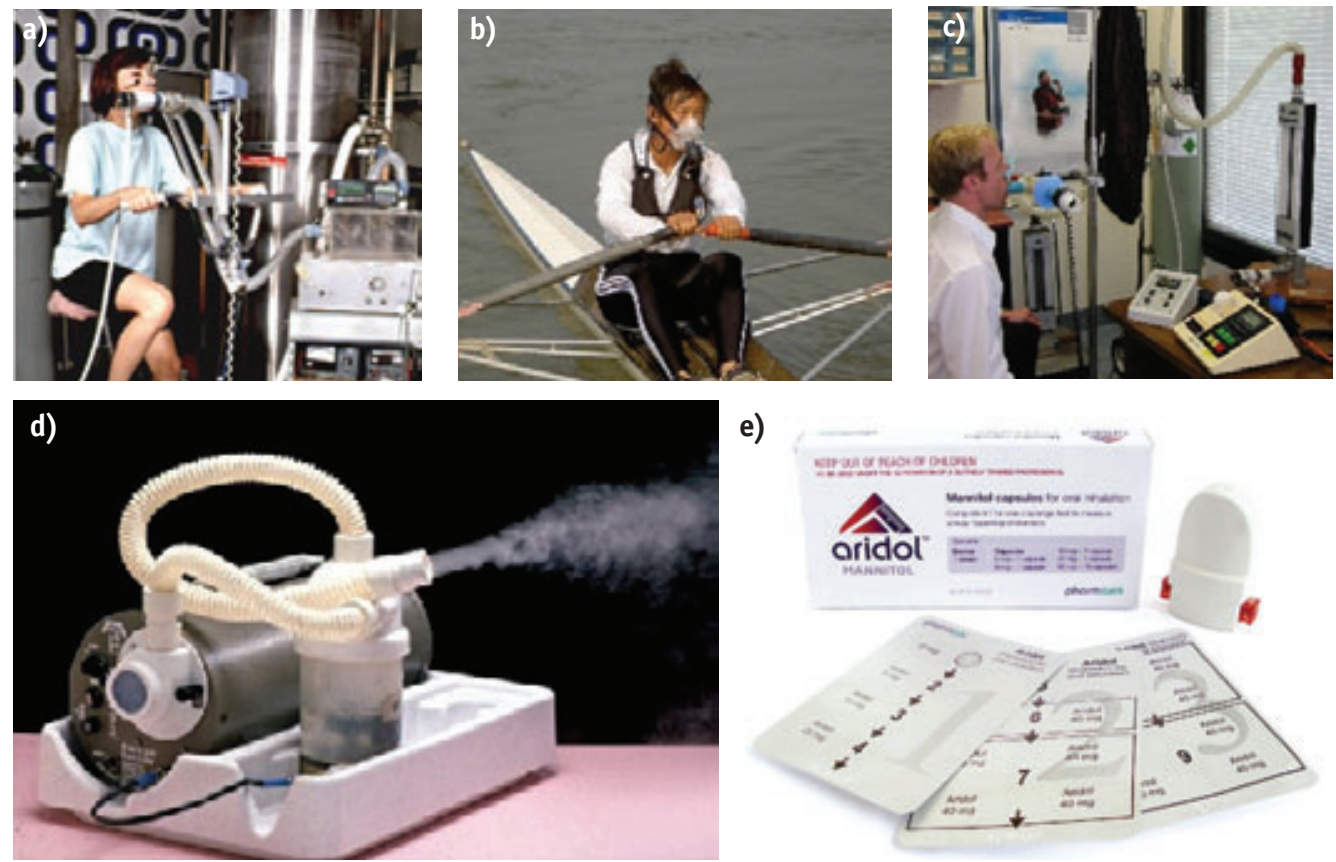

\section{Rationale and development}

The mannitol challenge test was developed in an attempt to make a bronchial provocation test that used one standardised protocol, gave reproducible findings and that was easy to perform as well as safe to use at the point of need [44]. Mannitol is a sugar alcohol and, like sodium chloride (saline), can act as an osmotic agent in physiological systems. In contrast to sodium chloride, mannitol is nonionic and is not easily or rapidly absorbed through the airway mucosa. Mannitol has advantages over sodium chloride in readily take up water and is stable and suitable dry powder formulation overcomes the technical problems in relation to variation in output of the wet aerosol particles over time using ultrasonic nebulisers. Finally, a dry-powder test overcomes the hygienic problems related to the generation of wet aerosols and the exposure of technical staff to these aerosols.

\section{Protocol}

For the mannitol test, the patient inhales increasing doses of dry-powder mannitol, with FEV1 measured in duplicate after each dose. The test protocol consists of $0 \mathrm{mg}$ (empty capsule), after which the baseline FEV1 is established, then 5, $10,20,40,80 \mathrm{mg}$ (2-40-mg capsules) and three doses of $160 \mathrm{mg}$ (4- 40-mg capsules) mannitol. The maximum cumulative dose of mannitol that is administered is $635 \mathrm{mg}$. The patient's FEV $\mathrm{V}_{1}$ is measured $60 \mathrm{~s}$ after administration of each dose, that, when prepared as a dry powder, it does not for encapsulation to be used for inhalation. The 
and the percentage change from the value measured after the 0-mg capsule is calculated [44]. The mannitol test needs to be performed in a timely manner so that the osmotic gradient is increased with each dose. The repeatability of the response to mannitol is one doubling-dose $[45,46]$.

The time to complete a positive test as observed in a large phase 3 trial was $17 \pm 7$ min for a positive test and $26 \pm 6$ min for a negative test [34]. A test taking $>35$ min may lead to a false negative result [47]. Sputum can also be collected for cell analysis during and after the mannitol challenge [48].

\section{Interpreting the response to mannitol}

A positive test result is defined as either a decrease in $\mathrm{FEV}_{1}$ of $15 \%$ from baseline (i.e. after $0 \mathrm{mg}$ capsule) or a $10 \%$ decrease in $\mathrm{FEV}_{1}$ between two consecutive doses [47]. The response to mannitol is expressed as the cumulative dose of mannitol that provokes a $15 \%$ decrease in $\mathrm{FEV}$ 1 (PD15 expressed in $\mathrm{mg}$ ). The severity of the airway response to mannitol is described in figure 7 . The mean decrease in $\mathrm{FEV} 1$ was $21.3 \pm 5.9 \%$; when a $15 \%$ fall was the target for diagnosis in a large phase 3 study [34].

The diagnostic validity of the mannitol challenge test has been assessed in three large clinical trials [34, 47, 49], which have consistently shown that the rate of false-positive tests in nonasthmatics is very low and that the mannitol test has a high specificity for currently active asthma. The sensitivity of mannitol to identify EIB in 375 adults and children with symptoms identified as possible, but not definite, asthma, was 59\% when EIB was defined as a $10 \%$ decrease in FEV 1 on at least one of two exercise tests [47]. The sensitivity increased to $69 \%$ when EIB was defined as a $15 \%$ decrease after exercise and to $75 \%$ when those with a mannitol test time of $\geq 35$ min were excluded. However, the frequency of a $15 \%$ decrease in $\mathrm{FEV} 1$ in response to mannitol was greater than that of a 15\% fall to exercise. The lower than expected sensitivity of mannitol to identify EIB in this population may reflect the mild nature of EIB, as $50 \%$ of subjects had a decrease of $<15 \%$ after exercise. Furthermore, the exercise response was variable, in that EIB, on the first exercise test, had a $62 \%$ sensitivity of identifying $\mathrm{EIB}$ on the second test. By contrast, in adults with known asthma and exercise-induced symptoms who had either a positive exercise test and/or a positive EVH test, $97 \%$ responded to mannitol and there was a good relationship with airway

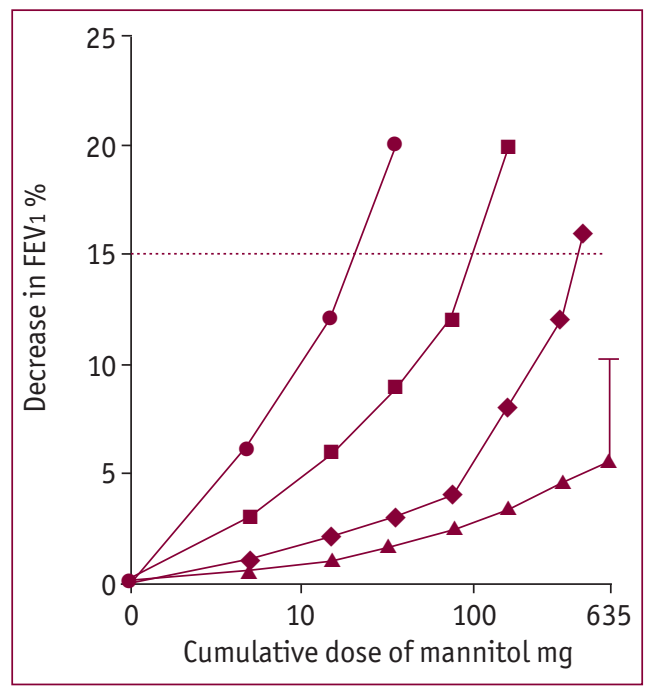

responses, particularly among steroid-naïve asthmatics (fig. 8) [24, 50]. In children with a clinical diagnosis of asthma and exercise-induced symptoms, nine out of 10 children (90\%) with a positive exercise test also responded to mannitol (15\% decrease in $\mathrm{FEV}_{1}$ ) [51].

In a group of elite athletes, the mannitol challenge test had a sensitivity of $96 \%$ and a specificity of $92 \%$ for detecting EIB defined as a positive EVH test, when using a cutoff of $10 \%$ for defining a positive mannitol test [22]. The sensitivity was reduced to $84 \%$ when a cutoff of a $15 \%$ decrease for mannitol was used. By contrast, a recent study of elite swimmers found little concordance between the mannitol test result and a swimming exercise test result; of the $14 \%$ responding to mannitol and the $16 \%$ responding to swimming exercise, only one swimmer responded to both tests [52]. Likewise, a study of cross-country skiers found that out of 23 subjects responding to methacholine, only two had a positive response to mannitol [53]. These

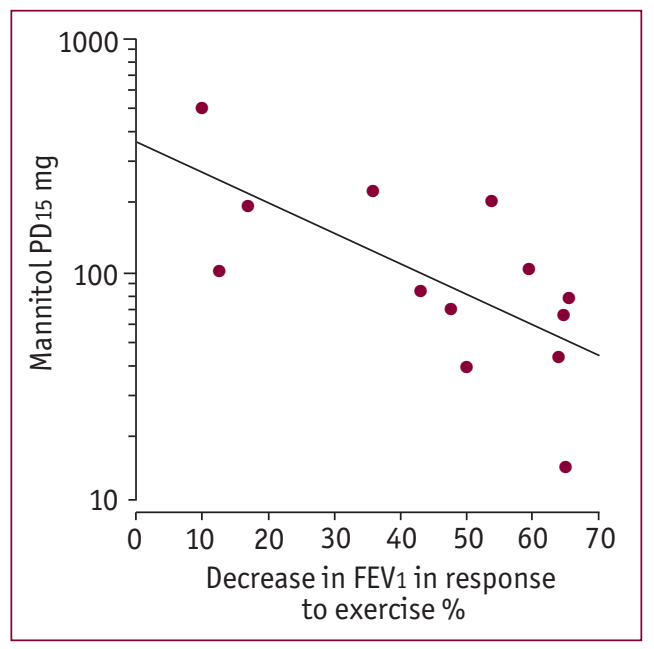

Figure 7

Classification of the airway response to a dry-powder aerosol of mannitol. This is calculated using the cumulative dose of mannitol (in $\mathrm{mg}$ ) that is encapsulated and delivered using a dry powder inhaler to provoke a $15 \%$ reduction in FEV1 from the FEV1 obtained following administration of the 0-mg capsule. The abnormal response is two standard deviations over the mean healthy response (normal; triangles). Circles: severe ( $\leq 35$ $\mathrm{mg})$; squares: moderate ( $\leq 155$ $\mathrm{mg})$; mild (>155 mg). Reproduced from [24], with permission from the publisher.

\section{Figure 8}

The airway sensitivity to inhaled mannitol in relation to the \% decrease in FEV1) following 8 min vigorous exercise in steroid-naïve subjects with established clinical asthma and exercise-induced bronchospasm. $r=-0.68 ; p<0.01$. Data from [24]. 
findings may be due to the different cut-off points used or different mechanisms being responsible for EIB in elite-level swimmers and cold-weather athletes [54]. The strongest relationship between airway sensitivity to mannitol and airway reactivity to exercise is in known asthmatics [24]. Elite athletes generally have milder EIB and the reproducibility of the responses may not be a feature of mild responses to indirect challenge tests [47]. EIB in elite athletes may be due to airway injury, such that there may be differences between those with EIB alone and subjects with EIB plus more chronic symptoms of asthma.

The mannitol challenge test has also been studied in groups working in occupations where EIB needs to be ruled out. In a group of firefighters, the mannitol test had a sensitivity of $92 \%$, a specificity of $97 \%$ and a positive predictive value and negative predictive value (NPV) of $86 \%$ and $98 \%$, respectively, for detecting asthma defined as a combination of symptoms and at least one objective sign of asthma [55]. The inclusion of BHR in the definition of the clinical diagnosis of asthma may explain the high sensitivity in this study. In comparison, a study using a primarily symptom-based diagnosis of asthma in 235 military conscripts found that the mannitol test had a low sensitivity (43\%) to detect subjects with a clinical diagnosis of asthma, but a high NPV (88\%) [56].

\section{Which test is the most appropriate to identify EIB?}

The choice of test will often depend on which tests are locally available and the overall test strategy may also depend on the need for an objective diagnosis of asthma (fig. 9). $\mathrm{EVH}$ is the most sensitive alternative test for EIB, particularly for elite-level athletes with good lung function. However, EVH requires specialised equipment and should be performed in a laboratory, which may limit its use to certain specialist clinics. Furthermore, there are safety issues in relation to large decreases in FEV 1 with any provocation test where the stimulus is given as a bolus

\begin{tabular}{|c|c|c|c|}
\hline \multicolumn{4}{|c|}{ Measure baseline FEV1 } \\
\hline$\nabla$ & $\nabla$ & $\downarrow$ & $\nabla$ \\
\hline $\begin{array}{l}\text { EVH (6-min) } \\
\text { MVV is calculated } \\
\text { from baseline FEV } 1 \\
\text { and is equal to MVV } \\
=35 \times \mathrm{FEV}_{1} \\
\\
\text { Encourage subject } \\
\text { to voluntarily } \\
\text { hyperventilate to } \\
\text { achieve } \geq 60 \% \text { MVV } \\
\text { throughout } 6 \text { min } \\
\text { On completion, } \\
\text { measure duplicate } \\
\text { FEV } 1 \text { values at } 1,3 \text {, } \\
5,10,15 \text { and } 20 \text { min } \\
\text { A positive test occurs } \\
\text { if a } \geq 10 \% \text { decrease at } \\
\text { two time points is } \\
\text { achieved after the } \\
\text { test }\end{array}$ & $\begin{array}{l}\text { EVH (progressive) } \\
\text { Calculate } 30,60 \text { and } \\
90 \% \text { MVV } \\
\text { Encourage subject to } \\
\text { voluntarily } \\
\text { hyperventilate } \\
\text { to achieve } 30 \% \text { MVV } \\
\text { for a 3-min period } \\
\text { On completion, } \\
\text { measure duplicate } \\
\text { FEV1 values at 1, } 2,5 \\
\text { and } 7 \text { min } \\
\\
\text { A positive test is } \\
\text { recorded and test is } \\
\text { stopped if a } \geq 10 \% \\
\text { decrease in FEV } 1 \text { is } \\
\text { achieved during this } \\
\text { time period. If not, } \\
\text { proceed to the next } \\
60 \% \text { MVV stage and, } \\
\text { if still negative, } \\
\text { proceed to } 90 \% \text { MVV }\end{array}$ & $\begin{array}{l}\text { Hyperosmolar saline } \\
\text { Calculate } 15 \% \\
\text { decrease from } \\
\text { baseline } \\
\text { Subject breathes } \\
\text { tidally to inhale } \\
\text { ultrasonically } \\
\text { nebulised } 4.5 \% \\
\text { hyperosmolar saline } \\
\text { for exposures of } 30 \mathrm{~s} \text {, } \\
1 \text { min, } 2 \text { min, } 4 \text { min } \\
\text { and } 8 \text { min } \\
\text { FEV } 1 \text { is measured in } \\
\text { duplicate } 60 \mathrm{~s} \\
\text { following each } \\
\text { exposure } \\
\text { A positive test occurs } \\
\text { once a } \geq 15 \% \\
\text { decrease in FEV } 1 \text { is } \\
\text { achieved following } \\
\text { any exposure period }\end{array}$ & $\begin{array}{l}\text { Mannitol } \\
\text { Subject inhales a } \\
0-\mathrm{mg} \text { capsule. } 60 \mathrm{~s} \\
\text { later, FEV } 1 \text { is } \\
\text { measured in } \\
\text { duplicate, baseline } \\
\text { FEV1 recorded } \\
\text { Calculate } 15 \% \\
\text { decrease from baseline } \\
\\
\text { Separate doses of } 5, \\
10,20,40,80(2 \times 40), \\
160 \text { (4×40), } 160 \text { mg } \\
\text { are administered. } 60 \mathrm{~s} \\
\text { after each dose, FEV } 1 \\
\text { measured in duplicate } \\
\text { A decrease } \geq 15 \% \text { in } \\
\text { FEV1 from baseline or } \\
\text { an incremental } \\
\text { (between-dose) } \\
\text { decrease of } 10 \% \text { at a } \\
\text { cumulative dose } \leq 645 \\
\text { mg is a positive test }\end{array}$ \\
\hline & & & \\
\hline \multicolumn{4}{|c|}{. } \\
\hline \\
\hline \multicolumn{4}{|c|}{ Measure post-bronchodilator $\mathrm{FEV}_{1}$} \\
\hline
\end{tabular}

Figure 9

Choice of test. \#: 85\% used for healthy elite athletes and recruits. 
rather than in progressively increasing doses. This safety issue applies equally to athletes and nonathletes, as the maximum airway response to EVH cannot be predicted from the baseline lung function. The hyperosmolar aerosol challenge tests are safer alternatives to $\mathrm{EVH}$, which makes them preferable in asthmatics in general and in nonelite athletes being assessed for BHR and EIB. Both hyperosmolar saline and mannitol require less equipment and the mannitol test can be performed in any clinical setting, as well as in the field. Both aerosol tests have been reported to have a low percentage of adverse events in phase 3 trials $[34,47]$. The mannitol test has practical advantages in being a simple, single-use test kit that is standardised and commercially available, and with regulatory approval that has made it more accessible to clinicians.

The hyperosmolar aerosol challenge tests have a lower sensitivity for detecting documented EIB compared with EVH. The agreement between a positive hyperosmolar test and a positive exercise test (i.e. positive responses to both tests) is highest in persons with classical asthma symptoms, and the agreement is least in persons without a definite diagnosis of asthma but who have mild symptoms.
The need for obtaining an objective diagnosis of asthma will determine the choice of test strategies: for instance, in the elite athlete, EVH is the most sensitive test to identify EIB and should be the test of choice if it is available. If $\mathrm{EVH}$ is not immediately available, a hyperosmolar aerosol challenge test may be applied first and, if it is negative, the athlete may be referred for EVH. In elite athletes applying for a Therapeutic Use Exemption (TUE) certificate to use asthma medications, both the EVH test, hypertonic saline and the mannitol test are recognised by the International Olympic Committee (IOC) and the World Anti-Doping Agency (WADA) as appropriate objective tests for identifying asthma. Methacholine and histamine are also accepted by the IOC and WADA for identifying BHR.

In asthmatics and non-elite athletes, hypero-smolar aerosols may be considered the firstchoice tests for practical reasons. Due to their lower sensitivity compared with EVH, retesting or assessment with several challenge tests may be required in cases where the suspicion of asthma is high based on symptoms or in cases where it is important to rule out asthma for persons who may be at risk of EIB due to an occupation or sporting activity.

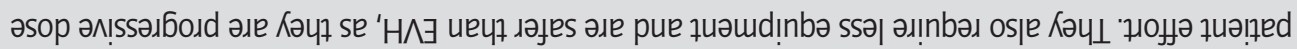

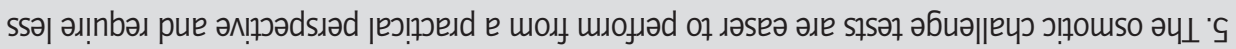

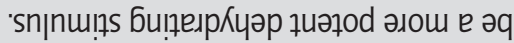
Кеш ұ! 'snц7 'əs! s|0з0101d әs!

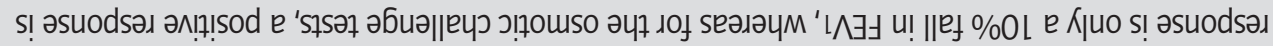

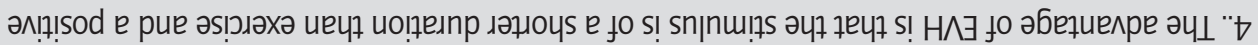

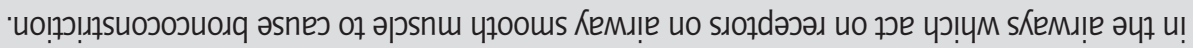

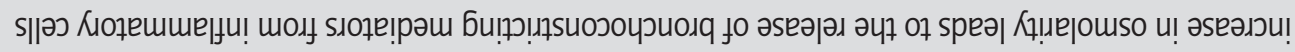

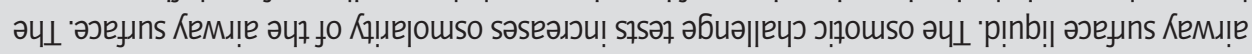

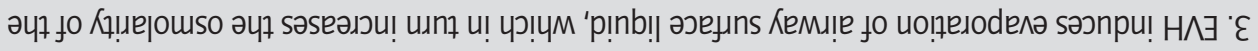

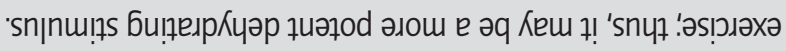

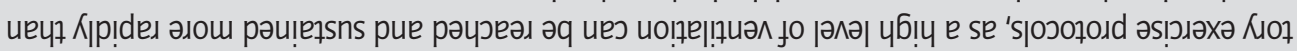

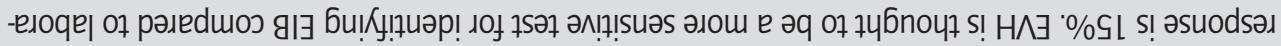

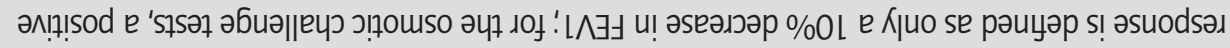

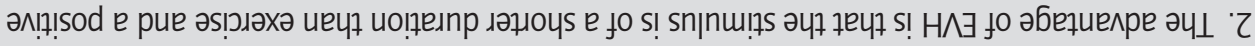

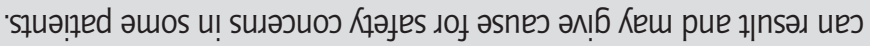

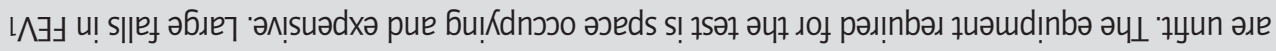

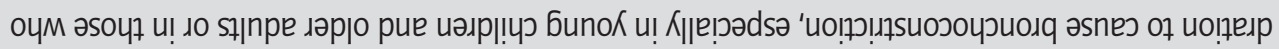

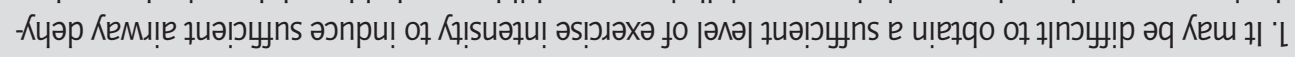




\section{References}

1. Silverman M, Anderson SD. Standardization of exercise tests in asthmatic children. Arch Dis Child 1972; 47: 882-889.

2. Eggleston PA. Laboratory evaluation of exercise-induced asthma: methodologic considerations. J Allergy Clin Immunol 1979; 64: 604S-608S.

3. Hull JH, Hull PJ, Parsons JP, et al. Approach to the diagnosis and management of suspected exercise-induced bronchoconstriction by primary care physicians. BMC Pulm Med 2009: 9: 29.

4. Brannan JD, Koskela H, Anderson SD. Monitoring asthma therapy using indirect bronchial provocation tests. Clin Respir J 2007; 1: 3-15.

5. Porsbjerg C, Brannan JD, Anderson SD, et al. Relationship between airway responsiveness to mannitol and to methacholine and markers of airway inflammation, peak flow variability and quality of life in asthma patients. Clin Exp Allergy 2008; 38: 43-50.

6. Duong M, Subbarao P, Adelroth E, et al. Sputum eosinophils and the response of exercise-induced bronchoconstriction to corticosteroid in asthma. Chest 2008; 133: 404-411.

7. Brannan JD. Bronchial hyperresponsiveness in the assessment of asthma control. Chest 2010: In Press.

8. Cockcroft D, Davis B. Direct and indirect challenges in the clinical assessment of asthma. Ann Allergy Asthma Immunol 2009; 103: 363-369.

9. Deal EC, McFadden ER, Ingram RH, et al. Hyperpnea and heat flux: initial reaction sequence in exercise-induced asthma. J Appl Physiol 1979; 46: 476-483.

10. Kivity S, Souhrada JF, Melzer E. A dose-response-like relationship between minute ventilation and exercise-induced bronchoconstriction in young asthmatic patients. Eur J Respir Dis 1980; 61: 342-346.

11. Hurwitz KM, Argyros GJ, Roach JM, et al. Interpretation of eucapnic voluntary hyperventilation in the diagnosis of asthma. Chest 1995; 108: 1240-1245.

12. Argyros GJ, Roach JM, Hurwitz KM, et al. Eucapnic voluntary hyperventilation as a bronchoprovocation technique. Development of a standardized dosing schedule in asthmatics. Chest 1996; 109: 1520-1524.

13. Brannan JD, Koskela H, Anderson SD, et al. Inhaled mannitol identifies responsiveness to eucapnic hyperventilation. Am J Respir Crit Care Med 1998; 157: A818.

14. Anderson SD, Argyros GJ, Magnussen H, et al. Provocation by eucapnic voluntary hyperpnoea to identify exercise induced bronchoconstriction. Br J Sports Med 2001; 35: 344-347.

15. Anderson SD, Brannan JD. Methods for "indirect" challenge testing including exercise, eucapnic voluntary hyperpnea, and hypertonic aerosols. Clin Rev Allergy Immunol 2003; 24: 27-54.

16. Zach M, Polgar G, Kump H, et al. Cold air challenge of airway hyperreactivity in children: practical application and theoretical aspects. Pediatr Res 1984; 18: 469-478.

17. Nielsen KG, Bisgaard $\mathrm{H}$. Lung function response to cold air challenge in asthmatic and healthy children of 2-5 years of age. Am J Respir Crit Care Med 2000; 161: 1805-1809.

18. Phillips $Y$ Y, Jaeger JJ, Laube BL, et al. Eucapnic voluntary hyperventilation of compressed gas mixture. A simple system for bronchial challenge by respiratory heat loss. Am Rev Respir Dis 1985; 131: 31-35.

19. Anderson SD, Lambert S, Brannan JD, et al. Laboratory protocol for exercise asthma to evaluate salbutamol given by two devices. Med Sci Sports Exerc 2001; 33: 893-900.

20. Brummel NE, Mastronarde JG, Rittinger D, et al. The clinical utility of eucapnic voluntary hyperventilation testing for the diagnosis of exercise-induced bronchospasm. J Asthma 2009; 46: 683-686.

21. Vathenen AS, Knox AJ, Wisniewski A, et al. Effect of inhaled budesonide on bronchial reactivity to histamine, exercise, and eucapnic dry air hyperventilation in patients with asthma. Thorax 1991; 46: 811-816.

22. Holzer K, Anderson SD, Chan H-K, et al. Mannitol as a challenge test to identify exercise-induced bronchoconstriction in elite athletes. Am J Respir Crit Care Med 2003; 167: 534-547.

23. Anderson SD, Caillaud C, Brannan JD. $\beta_{2}$-agonists and exercise-induced asthma. Clin Rev Immunol 2006; 31 : 163-180.

24. Brannan JD, Koskela H, Anderson SD, et al. Responsiveness to mannitol in asthmatic subjects with exercise- and hyperventilation-induced asthma. Am J Respir Crit Care Med 1998; 158: 1120-1126.

25. Smith CM, Anderson SD, Seale JP. The duration of action of the combination of fenoterol hydrobromide and ipratropium bromide in protecting against asthma provoked by hyperpnea. Chest 1988; 94: 709-717.

26. Anderson SD, Brannan JD. Methods for 'indirect' challenge tests including exercise, eucapnic voluntary hyperpnea and hypertonic aerosols. Clin Rev Allergy Immunol 2003; 24: 63-90.

27. Argyros GJ, Roach JM, Hurwitz KM, et al. The refractory period after eucapnic voluntary hyperventilation challenge and its effect on challenge technique. Chest 1995; 108: 419-424.

28. Bougault $V$, Boulet L-P, Turmel J. Bronchial challenges and respiratory symptoms in elite swimmers and winter sport athletes. Chest 2010; [Epub ahead of print D0I: 10.1378/chest.09-1689].

29. Rundell KW, Anderson SD, Spiering BA, et al. Field exercise vs laboratory eucapnic voluntary hyperventilation to identify airway hyperresponsiveness in elite cold weather athletes. Chest 2004; 125: 909-915.

30. Anderson SD, Schoeffel RE, Finney M. Evaluation of ultrasonically nebulised solutions as a provocation in patients with asthma. Thorax 1983; 38: 284-291.

31. Smith CM, Anderson SD. Inhalation provocation tests using non-isotonic aerosols. J Allergy Clin Immunol 1989; 84: 781-790.

32. Riedler J, Reade T, Dalton $M$, et al. Hypertonic saline challenge in an epidemiological survey of asthma in children. Am J Respir Crit Care Med 1994; 150: 1632-1639.

33. Riedler J, Gamper A, Eder W, et al. Prevalence of bronchial hyperresponsiveness to $4.5 \%$ saline and its relation to asthma and allergy symptoms in Austrian children. Eur Respir J 1998; 11: 355-360.

34. Brannan JD, Anderson SD, Perry CP, et al. The safety and efficacy of inhaled dry powder mannitol as a bronchial provocation test for airway hyperresponsiveness: a phase 3 comparison study with hypertonic (4.5\%) saline. Respir Res 2005; 6: 144.

35. Gibson PG, Saltos N, Borgas T. Airway mast cells and eosinophils correlate with clinical severity and airway hyperresponsiveness in corticosteroid-treated asthma. J Allergy Clin Immunol 2000; 105: 752-759.

36. du Toit JI, Anderson SD, Jenkins CR, et al. Airway responsiveness in asthma: bronchial challenge with histamine and 4.5\% sodium chloride before and after budesonide. Allergy Asthma Proc 1997; 18: 7-14.

37. de Meer G, Postma DS, Janssen NA, et al. Bronchial hyper-reponsiveness to hypertonic saline and blood eosinophilic markers in 8-13 year old school children. Clin Exp Allergy 2004; 34: 1226-1231. 
38. Anderson SD, du Toit JI, Rodwell LT, et al. Acute effect of sodium cromoglycate on airway narrowing induced by 4.5 percent saline aerosol. Outcome before and during treatment with aerosol corticosteroids in patients with asthma. Chest 1994; 105: 673-680.

39. Aldridge RE, Hancox RJ, Robin Taylor D, et al. Effects of terbutaline and budesonide on sputum cells and bronchial hyperresponsiveness in asthma. Am J Respir Crit Care Med 2000; 161: 1459-1464.

40. Brannan JD, Koskela H, Anderson SD. Monitoring asthma therapy using indirect bronchial provocation tests. Clin Resp J 2007; 1: 3-15.

41. Smith CM, Anderson SD. Inhalational challenge using hypertonic saline in asthmatic subjects: a comparison with responses to hyperpnoea, methacholine and water. Eur Respir J 1990; 3: 144-151.

42. Boulet L-P, Turcotte H, Tennina S. Comparative efficacy of salbutamol, ipratropium and cromoglycate in the prevention of bronchospasm induced by exercise and hyperosmolar challenges. J Allergy Clin Immunol 1989; 83: 882-887.

43. Belcher NG, Lee TH, Rees PJ. Airway responses to hypertonic saline, exercise and histamine challenges in bronchial asthma. Eur Respir J 1989; 2: 44-48.

44. Anderson SD, Brannan J, Spring J, et al. A new method for bronchial-provocation testing in asthmatic subjects using a dry powder of mannitol. Am J Respir Crit Care Med 1997; 156: 758-765.

45. Brannan JD, Anderson SD, Gomes K, et al. Fexofenadine decreases sensitivity to and montelukast improves recovery from inhaled mannitol. Am J Respir Crit Care Med 2001; 163: 1420-1425.

46. Barben J, Roberts $M$, Chew N, et al. Repeatability of bronchial responsiveness to mannitol dry powder in children with asthma. Pediatr Pulmonol 2003; 36: 490-494.

47. Anderson SD, Charlton B, Weiler JM et al. Comparison of mannitol and methacholine to predict exercise-induced bronchoconstriction and a clinical diagnosis of asthma. Respir Res 2009; 10: 4.

48. Wood LG, Powell H, Gibson PG. Mannitol challenge for assessment of airway responsiveness, airway inflammation and inflammatory phenotype in asthma. Clin Exp Allergy 2010; 40: 232-241.

49. Sverrild A, Porsbjerg C, Thomsen SF, et al. Diagnostic properties of inhaled mannitol in the diagnosis of asthma: a population study. J Allergy Clin Immunol 2009; 124: 928-932.

50. Munoz PA, Gomez FP, Manrique HA, et al. Pulmonary gas exchange response to exercise- and mannitol-induced bronchoconstriction in mild asthma. J Appl Physiol 2008; 105: 1477-1485.

51. Kersten ET, Driessen JM, van der Berg JD, et al. Mannitol and exercise challenge tests in asthmatic children. Pediatr Pulmonol 2009; 44: 655-661.

52. Clearie KL, Williamson PA, Vaidyanathan S, et al. Disconnect between standardized field-based testing and mannitol challenge in Scottish elite swimmers. Clin Exp Allergy 2010; 40: 731-737.

53. Sue-Chu M, Brannan JD, Anderson SD, et al. Airway hyperresponsiveness to methacholine, adenosine 5-monophosphate, mannito, eucapnic voluntary hyperpnoea and field exercise challenge in elite cross country skiers. Brit J Sports Med 2010; [Epub ahead of print D0I: 10.1136/bjsm.2009.071043].

54. Anderson SD, Kippelen P. Airway injury as a mechanism for exercise-induced bronchoconstriction in elite athletes. J Allergy Clin Immunol 2008; 122: 225-235.

55. Miedinger D, Chhajed PN, Tamm M, et al. Diagnostic tests for asthma in firefighters. Chest 2007; 131: 1760-1767.

56. Miedinger D, Mosimann N, Meier R, et al. Asthma tests in the assessment of military conscripts. Clin Exp Allergy 2010; 40: 224-231. 